\title{
Crowdsourcing in medical research: concepts and applications
}

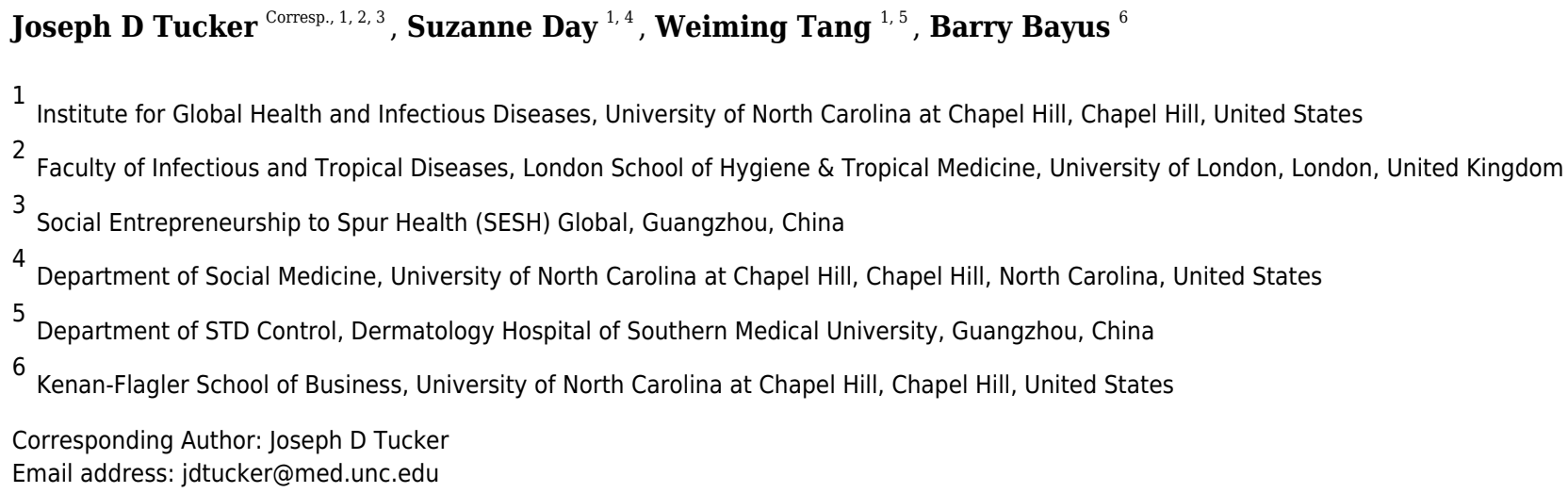

Crowdsourcing shifts medical research from a closed environment to an open collaboration between the public and researchers. We define crowdsourcing as an approach to problem solving which involves an organization having a large group attempt to solve a problem or part of a problem, then sharing solutions. Crowdsourcing allows large groups of individuals to participate in medical research through innovation challenges, hackathons, and related activities. The purpose of this literature review is to examine the definition, concepts, and applications of crowdsourcing in medicine. This multi-disciplinary review defines crowdsourcing for medicine, identifies conceptual antecedents (collective intelligence and open source models), and explores implications of the approach. Several critiques of crowdsourcing are also examined. Although several crowdsourcing definitions exist, there are two essential elements: (1) having a large group of individuals, including those with skills and those without skills, propose potential solutions; (2) sharing solutions through implementation or open access materials. The public can be a central force in contributing to formative, pre-clinical, and clinical research. A growing evidence base suggests that crowdsourcing in medicine can result in high-quality outcomes, broad community engagement, and more open science. 


\section{Crowdsourcing in medical research: concepts and} 2 applications

3

4 Joseph D. Tucker, ${ }^{1,2,3}$ Suzanne Day, ${ }^{1,4}$ Weiming Tang,,${ }^{1,2,5}$ Barry Bayus ${ }^{6}$

$5{ }^{1}$ Institute for Global Health and Infectious Diseases, University North Carolina at Chapel Hill, 6 Chapel Hill, USA

$7 \quad 2$ Social Entrepreneurship to Spur Health (SESH) Global, Guangzhou, China

$8{ }^{3}$ Faculty of Infectious and Tropical Diseases, London School of Hygiene and Tropical Medicine, 9 London, United Kingdom

$10{ }^{4}$ Department of Social Medicine, University North Carolina at Chapel Hill, Chapel Hill, North 11 Carolina, United States

$12{ }^{5}$ Department of STD Control, Dermatology Hospital of Southern Medical University, 13 Guangzhou, China ${ }^{6}$ Kenan-Flagler School of Business, University North Carolina at Chapel Hill, Chapel Hill, USA

Corresponding Author Contact Information: Dr Joseph Tucker, UNC Project-China, 2 Lujing 


\section{Abstract}

27

28

29

Crowdsourcing shifts medical research from a closed environment to an open collaboration between the public and researchers. We define crowdsourcing as an approach to problem solving which involves an organization having a large group attempt to solve a problem or part of a problem, then sharing solutions. Crowdsourcing allows large groups of individuals to participate in medical research through innovation challenges, hackathons, and related activities. The purpose of this literature review is to examine the definition, concepts, and applications of crowdsourcing in medicine. This multi-disciplinary review defines crowdsourcing for medicine, identifies conceptual antecedents (collective intelligence and open source models), and explores implications of the approach. Several critiques of crowdsourcing are also examined. Although several crowdsourcing definitions exist, there are two essential elements: (1) having a large group of individuals, including those with skills and those without skills, propose potential solutions; (2) sharing solutions through implementation or open access materials. The public can be a central force in contributing to formative, pre-clinical, and clinical research. A growing evidence base suggests that crowdsourcing in medicine can result in high-quality outcomes, broad community engagement, and more open science. 
48

49

50

51

52

53

54

\section{Introduction}

Crowdsourcing is an approach to problem solving that has gained momentum in the past decade.(Han et al. 2018; Pan et al. 2017) Crowdsourcing involves an organization having a large group attempt to solve a problem or a component of a problem, then sharing solutions.(van Ess 2010) This concept has facilitated ways for the public to engage in medical research, including innovation challenges (also called prize competitions, prize contests, or open contests), hackathons, online systems for collaboration, and other activities (Table 1).(Brabham et al. 2014; Pan et al. 2017; Ranard et al. 2014) We define medicine as the science and practice of preventing, diagnosing, and treating human disease.(2019) Crowdsourcing is related to open innovation, diverging from conventional closed innovation medical research in several ways (Table 2).(Chesbrough 2003)

Systematic reviews(Crequit et al. 2018; Ranard et al. 2014) and a World Health Organization practical guide on crowdsourcing(Han et al. 2018) demonstrate a growing evidence base supporting crowdsourcing in medicine. Some crowdsourcing projects have asked groups to develop health communication materials (e.g., images, videos) to promote HIV, hepatitis, and STI testing.(Tang et al. 2018; Zhang et al. 2017b; Zhang et al. 2015) Others have used crowdsourcing to accelerate antibiotic and other drug development.(Desselle et al. 2017; Grammer et al. 2016; Shaw 2017; Tuffery 2015) However, this literature has not examined broader concepts and applications related to crowdsourcing in medicine. 
69 The diversity of crowdsourcing approaches complicates attempts to achieve a single overarching

70 conceptual framework.(Ringh et al. 2015; Tang et al. 2016a) Some have suggested that

71 crowdsourcing lacks a strong conceptual foundation.(Geiger et al. 2011a) Others argue that the

72 relatively brief history of crowdsourcing makes it premature to consider conceptual or theoretical

73 elements.(Geiger et al. 2011b) However, the conceptual basis of crowdsourcing reaches well

74 beyond the first use of the term. This history alongside more recent data on collective

75 intelligence and open-source models pave the way for a better understanding of crowdsourcing

76 concepts and applications.

\section{Review Methodology}

This literature review examined the peer-reviewed and gray literature on crowdsourcing approaches related to medicine. We searched PubMed, Google Scholar, ResearchGate, and Academia.edu to identify potential studies for inclusion on February $25^{\text {th }} 2019$. We focused on manuscripts that defined conceptual issues and applications of crowdsourcing for medical research. We excluded studies that were not in English. This manuscript defines crowdsourcing for medicine, identifies conceptual antecedents, considers relationships with other approaches, and examines common critiques.

\section{Crowdsourcing: A Definition}

88 There have been many definitions of crowdsourcing since Jeff Howe coined the term in

89 2005.(Brabham 2008; Howe 2006; Ranard et al. 2014; Tang et al. 2018; Wazny 2017) The term is a portmanteau composed of "crowd" and "outsourcing." The original definition was applied to 
91 describe companies outsourcing tasks to a group of individuals who worked collectively or

92 individually. Howe himself realized that this initial definition was overly narrow and later

93 expanded it to include the application of open-source principles to fields outside of software.

94 However, this definition and many of the existing ones(Brabham 2008; Ranard et al. 2014) do

95 not include the subsequent obligation to share solutions. Henk van Ess suggested that

96 crowdsourcing involves those with skills and those without skills attempting to solve a problem,

97 then freely sharing some solutions with the public.(van Ess 2010) We have included the sharing

98 component for the following reasons: crowdsourcing activities draw on the strength of many

99 laypeople who will not receive incentive prizes (e.g., gifts, money, mentorship, or other

100 benefits); there are ethical problems with leveraging group insights (either individually or

101 collectively) and not giving back to the group(Tucker et al. 2018); not sharing would likely

102 diminish enthusiasm for sustained engagement from those who contribute to challenges; sharing

103 may be more likely to advance medical knowledge. Many individuals who participate in

104 crowdsourcing activities report altruistic motivations, hoping to help their community or the

105 public at large.(2018b; Mathews et al. 2018; Zhang et al. 2017b) Including a sharing component

106 fulfills this obligation to give back to the public.

First, an organization has a group (including those with skills and those without skills) attempt to solve a problem. The group could be working independently or collaborating as a team. The rationale for sourcing solutions from a group rather than select individuals includes the

111 following: (1) the potential for groups to have relevant knowledge and experiences in a related

112 field; (2) the importance of public participation and community consultation in health services;

113 (3) the potential for local end-users, patients, and others to be more actively engaged in the 
114 process of developing new ideas; (4) the inclusion of people from the community to assist in

115 designing interventions that would be feasible and relevant in the local community. The group

116 participation component of crowdsourcing has been used by states, international organizations,

117 and non-profits for centuries. For example, in 1714, the British government wanted to find an

118 accurate method to measure a ship's longitudinal position. They offered a cash prize to

119 whomever developed a solution that met pre-specified benchmarks. This spurred many groups to

120 focus on enhanced methods for measuring longitude, resulting in important advances in this

121 field.(2009)

123 The second key component of crowdsourcing involves sharing solutions. This could be

124 accomplished through implementing the solution in a local community(Tang et al. 2018) or

125 creating open access materials for public use.(Wu et al. 2018) For example, the rights to an

126 exceptional crowdsourced image could be made widely available through creative commons

127 attribution. Crowdsourcing approaches may generate a range of materials and products that can

128 be shared in both digital and in-person formats. Some examples of ways that crowdsourced

129 materials have been shared include: providing crowdsourced images, concepts, and logos to the

130 public through an open access website;(Wu et al. 2018) widely distributing images through

131 social media;(Zhang et al. 2015) evaluating the effectiveness of the crowdsourced output through

132 a trial;(Tang et al. 2016a; Tang et al. 2016c; Tang et al. 2018) holding a series of in-person

133 workshops to communicate crowdsourced findings with key stakeholders.(Zhang et al. 2017a) 
135 These two crowdsourcing components - group participation and sharing solutions - are each

136 indebted to earlier multidisciplinary concepts on collective intelligence and open source models,

137 respectively. The next two section explores these related concepts as they inform crowdsourcing.

\section{Collective Intelligence}

140 Collective intelligence suggests that in certain settings, a group is better able to solve difficult

141 problems than an individual working alone. The concept is not a universal statement about

142 groups being wiser than individuals, but rather that there are certain contexts wherein this is true.

143 The collective intelligence concept has a history in political science, philosophy, social science,

144 and biology. Perhaps the earliest mention of this concept was in 1785 when Marquis de

145 Condorcet published a theorem about the relative probability of a given group of individuals

146 arriving at a correct decision.(de Condorcet 1785) The theorem examines the optimal number of

147 voters when engaging in a group decision. The number is greater when there is a higher

148 probability of each voter making a correct decision; the number is small when there is a lower

149 probably of each voter making a correct decision. This provides a theoretical basis for

150 democracy and has been widely used in political science.(Austen-Smith \& Banks 1996; Ladha

151 1992) Within a health context, Condorcet's theorem has been used in clinical diagnostic

152 imaging(Gottlieb \& Hussain 2015) and reviewing organ transplant eligibility.(Koch \& Ridgley

153 2000)

Philosophers and others have contributed to the development of a collective intelligence concept.

156 The French philosopher Pierre Lévy defined collective intelligence as "a form of universally 
157 distributed intelligence, constantly enhanced, coordinated in real time, and resulting in effective

158 mobilization of skills."(Lévy 1997) Social reformers have also used collective intelligence as a

159 key guiding principle. H. G. Wells described a "World Brain" concept that would help citizens to

160 share information as a group,(Wells 1938) benefiting from local knowledge and experience

161 within a common platform. He envisioned the platform as a non-commercial resource that would

162 span political boundaries and help expand knowledge.(Wells 1938) The crowdsourced

163 encyclopedia, Wikipedia, echoes some of the structures and functions of Wells' original world

164 brain concept.

166 Empirical evidence from humans suggests that in some contexts, a convergent collective

167 intelligence factor explains a group's performance on several tasks.(Woolley et al. 2010) Further

168 empirical evidence supporting collective intelligence is summarized in James Surowiecki's The

169 Wisdom of Crowds.(Surowiecki 2004) He argues that four elements are necessary for collective

170 intelligence - diversity of opinion, independence of individual ideas, decentralization of ideas,

171 and a way to aggregate individual ideas. Surowiecki shows how collective intelligence has been

172 used in many different contexts, ranging from prediction markets to the Delphi method. The

173 Delphi method has a group of individuals iteratively answer questions and converge on a single

174 answer. The method has been widely used to achieve group consensus in health

175 guidelines.(Diamond et al. 2014)

177 Collective intelligence approaches have been evaluated in several medical settings. Research

178 among medical students suggests that groups of medical students have increased diagnostic 
179 performance compared to individual medical students.(Hautz et al. 2015; Kammer et al. 2017)

180 Similar approaches have been evaluated in the context of physician diagnosis of skin

181 cancer(Kurvers et al. 2016) and breast cancer.(Wolf et al. 2015)

Open Source Model

184 Open source models can inform the second important component of crowdsourcing - sharing

185

186

187

188

189

190

191

192

193

194

195

196

197

198

199

200 solutions. Open source refers to a decentralized structure that facilitates collaboration and online sharing. Open source models were developed in the 1960s and 1970s as a way to collaboratively develop software and share code.(von Hippel \& von Krogh 2003) In 1969, the United States Advanced Research Project Agency created the first large, high-speed computer network. This extended opportunities for sharing code among broader online groups. For example, the Linux operating system is one of the first open source operating systems, shared online and available for free to anyone. Linus Torvalds developed the source code for this operating system by sending it to other internet users who helped improve it on a volunteer basis. The collective development of open source products, such as Linux, demonstrate how large, diverse groups working together can iteratively enhance a product that is openly available, to the benefit of all.

This trend also led to the development of Creative Commons, a non-profit organization that allows individuals to legally change and share creative works. The organization has a series of copyright licenses that clarify the terms of sharing. There are currently approximately 1.4 billion works that have been licensed through Creative Commons. 
201 Open source models have increasingly appeared in medicine. For example, several drug

202 development projects have used open source models.(Bombelles \& Coaker 2015; Munos 2006;

203 Munos 2010; So et al. 2011) A project called Open Source Pharma focuses on developing drugs

204 through open source methods. Thousands of volunteers from over 100 countries have helped

205 with micro-tasks to develop more effective drugs for tuberculosis, schistosomiasis, and other

206 infectious diseases.(Bhardwaj et al. 2011) The open source platform has resulted in high-quality

207 research, including advances related to the development of schistosomiasis drugs.(Ardal \&

208 Rottingen 2012) Other open source models for drug discovery have been developed for

209 Huntington's disease,(Wilhelm 2017) malaria,(Ardal \& Rottingen 2015) eumycetoma,(Lim et al.

210 2018) and other diseases.(Bagla 2012)

212 Open source models have also been used within genomics. A Shiga-toxin producing E. coli

213 outbreak occurred in Germany in 2011, infecting 3000 individuals. Scientists used an open

214 source model to organize the analysis of a genome sequence from a single individual. The

215 collaborative effort brought together volunteers from around the world, creating the genome

216 sequence within two weeks of receiving the DNA samples.(Rohde et al. 2011) In addition, the

217 DREAMS Challenge team has organized many open source innovation challenges.(Saez-

218 Rodriguez et al. 2016) These typically involve volunteers collaboratively working together to

219 solve a problem related to big data and genomics. Several evaluations of this approach have

220 found it to be effective in developing prognostic models based on clinical data.(Allen et al. 2016;

221 Guinney et al. 2017; Noren et al. 2016) Both collective intelligence and open source models

222 reveal some of the theoretical antecedents of crowdsourcing. 


\section{Relationship to Other Research Approaches}

225 Crowdsourcing as an approach is distinct from, but related to community-based participatory

226 research, participatory action research, and community-driven research. Each of these different

227 approaches has a conceptual framework, methods, and assumptions. At the same time, each of

228 these three approaches can be used to inform medical research.

230 Community-based participatory research actively engages the community in all stages of the

231

232

233

234

235

236

237

238

239

240

241

24

research process, contributing to shared decision making and community ownership.(Minkler \& Wallerstein 2003) The community plays a central force in setting the agenda, implementing the study, and evaluating the results, such that local community members and researchers iteratively collaborate to improve the health of the community. Similarities between community-based participatory research and crowdsourcing include the following: a focus on listening to and partnering with local communities; a potential to increase healthy equity; an acknowledgement that communities can be a powerful source of new ideas. These areas of convergence suggest that community-based participatory research could be a useful complement to crowdsourcing. For example, community-based participatory research was used to increase community engagement in an HIV cure research project.(Mathews et al. 2018)

Other related approaches include participatory action research and youth participatory action research. Participatory action research focuses on partnering with communities to participate in research and achieve social change.(Bradbury 2015) Youth participatory action research provides youth with opportunities to learn about social problems that affect their lives and then 
246 propose actions to address these problems.(Cammarota \& Fine 2008; Cammarota \& Fine 2010;

247 Kirshner 2010; Ozer et al. 2016) The participatory action approach considers youth as potential

248 experts and co-creators of knowledge.(Ozer 2016) Shared elements of crowdsourcing and

249 participatory research approaches include the emphasis on participation, local community

250 partnerships, and empowerment of the public. Participatory action research has been used to

251 complement crowdsourcing projects related to environmental health(English et al. 2018) and to

252 design crowdsourcing approaches for HIV self-testing.(2018c)

254 Finally, community-driven research is another approach related to crowdsourcing. Community-

255 driven research has community members and researchers collaboratively design, implement,

256 analyze, interpret, and disseminate research findings.(Orionzi et al. 2016) Community-driven

257 research starts with an assessment of local priorities from the perspective of the community.

258 Both community-driven research and crowdsourcing focus on community-led research,

259 developing ideas and programs from the bottom-up for the community.(McElfish et al. 2015)

260 All three of these approaches have been used in health research. We now turn to examine

261 crowdsourcing specifically in the context of health.

262

263 Critiques of Crowdsourcing

264 There are three main critiques of crowdsourcing that merit consideration - the madness of groups

265 concept, the problem of low-quality submissions, and cognitive fixation on examples. We will

266 examine each of these critiques generally and then in the context of crowdsourcing as it applies

267 to medicine. 
269 First, the madness of groups refers to the potential for groups to create and disseminate popular

270 delusions, contributing to panic and moral outrage.(Mackay 1852) The nineteenth century

271 journalist Charles Mackay remarked, "Men, it has been said, think in herds; it will be seen that

272 they go mad in herds, while they only recover their senses slowly, and one by one."

273 Psychologists have examined how individual behaviors contribute to and diverge from the

274 collective behavior of the groups. Group behavior may be associated with a loss of

275 responsibility. This is illustrated in the case of Boaty McBoatface, a boat name chosen from a

276 public online poll in the United Kingdom. This name was the most popular in the

277 \#NameOurShip poll, but ultimately not used to name the ship.(Ellis-Petersen 2016) One example

278 of mad crowds in the context of medicine is low vaccine uptake. Several negative social media

279 reports that spread through online networks have influenced vaccine uptake and disease

280 outbreaks.(Larson et al. 2013)

However, crowdsourcing as an approach does not suggest that all groups are wise at all times, but rather that there are specific conditions that can allow for wise groups. In addition, several individuals have made rebuttals and clarified the concept of a mad group. Clark McPhail has shown how mad groups are primarily the result of individuals, rather than a group disposition.(McPhail 1991) Empirical data on whether group behavior results in a loss of responsibility has been mixed.(Manstead \& Hewstone 1995) Within the context of medicine, online platforms have propagated myths and misunderstandings about disease.(Lavorgna et al. 2017; Powell et al. 2016) Submissions to innovation challenges may include myths,(Mathews et al. 2018) but judging typically finds these submissions of lower quality. Other ways to limit the 
291 risk of mad crowds is to have multi-phase challenges with vetting(Fitzpatrick et al. 2018) or

292 online moderation of submission platforms.(Rice et al. 2016)

294 Second, crowdsourcing projects are sometimes associated with many low-quality outputs. A

295 systematic review of crowdsourcing suggests that only a subset of outputs are excellent.(Pan et

296 al. 2017) Having those without formal training contribute to a more complex medical project will

297 result in a wide range of outputs, especially when mass engagement translates into hundreds of

298 submissions. However, the ability to prompt a large number of submissions is an advantage of

299 crowdsourcing and suggests that a wider group of individuals is actively participating. Several

300 techniques for judging have been developed to assess large numbers of crowdsourcing

301 contributions,(Han et al. 2018) including group judging (having a group of individuals

302 evaluate),(Tang et al. 2018) panel judging (having a diverse group of individuals

303 evaluate),(Zhang et al. 2015) and artificial intelligence.(Albarqouni et al. 2016; Mudie et al.

304 2017) Several systematic reviews of crowdsourcing in medicine suggest that crowdsourcing 305 allows a broad range of quality, including both low and high-quality submissions.(Crequit et al.

306 2018; Dai et al. 2017; Ranard et al. 2014)

307

308 Finally, the problem of cognitive fixation on prior ideas has been described in crowdsourcing.(Fu

309 et al. 2017) This refers to the phenomenon when providing an example or reference limits the

310 diversity of ideas solicited. This concept is similar to groupthink, which occurs when a group of

311 individuals converges on a single solution.(Janis 1972) There are several technical ways of

312 designing a crowdsourcing project that could limit cognitive fixation, including the following: 
313 limiting the use of examples when calling for innovative ideas; drawing on different groups of

314 individuals or different topics (avoiding serial challenges focused on the same topic); and having

315 a submission system in which those who submit do not view other submissions.

\section{Crowdsourcing Applications in Medical Research}

318 Crowdsourcing approaches have already been used to enhance formative, pre-clinical, and

319 clinical research (Table 3). Crowdsourcing approaches have been used to assist in the discovery 320 and development of antibiotics,(Desselle et al. 2017) lupus drugs,(Grammer et al. 2016) and anti-

321 malarials.(Spangenberg et al. 2013) Several crowdsourcing activities have been used to prepare

322 for clinical and other medical research. Crowdsourcing approaches have identified potentially

323 relevant citations as part of systematic reviews. This approach has been found

324 reliable(Mortensen et al. 2017) and is being piloted as part of a Cochrane program.(2018a)

Crowdsourcing could accelerate several stages of drug development, including screening, preclinical trials, and human clinical trials. Screening of potential drug candidates has been opened to the public through crowdsourcing activities in several fields. The Medicines for Malaria Venture(Spangenberg et al. 2013) and a tuberculosis consortium(Ballell et al. 2013) both used crowdsourcing to catalyze drug target identification. At the pre-clinical stage of drug development, sharing of chemical probes with the public has created a new class of bromodomain inhibitors.(Arshad et al. 2016; Scott 2016) Within human trials, several studies have used crowdsourcing to develop human clinical trial study messaging and community engagement.(Leiter et al. 2014; Mathews et al. 2017; Pan et al. 2017) Many studies have used 
335 Amazon Turk or other platforms to recruit study participants into online randomized controlled

336 trials.(Jones et al. 2013; Losina et al. 2017; Tang et al. 2016a; Tang et al. 2016b) While such

337 approaches are often rapid and save money, there are concerns about generalizability.(Wang et

338 al. 2017)

340 Conclusion

341 Our observations about using crowdsourcing in medical research have several important

342 limitations. First, we did not focus our analysis based on different categories of crowdsourcing

343 because other systematic reviews have covered this territory.(Crequit et al. 2018; Wang et al.

344 2018) Second, although there is a growing literature on crowdsourcing in medical research,(Pan

345 et al. 2017) the number of randomized controlled trials and related studies is still limited.(Wang

346 et al. 2018) Third, we have not included a list of areas which problems may be more amenable to

347 crowdsourcing because this has been partially covered in a previous review(Wazny 2017) and is

348 difficult to infer from the existing literature.

350 This review suggests several important areas for future crowdsourcing research in medicine.

351 More rigorous research studies are needed to expand our understanding of crowdsourcing,

352 including studies with comparator groups (e.g., randomized controlled trials), cost-effectiveness

353 research, and qualitative studies. In addition, given that much of the crowdsourcing medical

354 research to date has benefitted from academic medical schools as innovation hubs,(Siefert et al.

355 2018) further development of crowdsourcing in medical training and education may be

356 warranted. The design of innovation challenges is widely known among practitioners to 
357 influence the ultimate success of crowdsourcing activities, but these design elements are not

358 frequently captured in studies. Further methodological innovation and research are needed.

\section{References}

2009. And the winner is...: Capturing the promise of philanthropic prizes. Available at

http://mckinseyonsociety.com/downloads/reports/Social-Innovation/And the winner_is.pdf.

2018a. Cochrane Crowd. Available at http://community.cochrane.org/tools/data-managementtools/cochrane-crowd.

2018b. DREAM Challenges. Available at http://dreamchallenges.org/about-dream/.

2018c. ITEST: Innovative Tools to Expand Youth-Friendly HIV Self-Testing. Available at https://projectreporter.nih.gov/project info description.cfm?aid $=9618360 \& i c d e=41536786 \& d d$ param $=\& d d$ value $=\& d d s u b=\& c r=1 \& c s b=$ default \&cs=ASC\&pball $=$.

2019. Oxford English Dictionary. Oxford, UK: Oxford University Press.

Albarqouni S, Baur C, Achilles F, Belagiannis V, Demirci S, and Navab N. 2016. AggNet: Deep Learning From Crowds for Mitosis Detection in Breast Cancer Histology Images. IEEE Trans Med Imaging 35:1313-1321. 10.1109/TMI.2016.2528120

Allen GI, Amoroso N, Anghel C, Balagurusamy V, Bare CJ, Beaton D, Bellotti R, Bennett DA, Boehme KL, Boutros PC, Caberlotto L, Caloian C, Campbell F, Chaibub Neto E, Chang YC, Chen B, Chen CY, Chien TY, Clark T, Das S, Davatzikos C, Deng J, Dillenberger D, Dobson RJ, Dong Q, Doshi J, Duma D, Errico R, Erus G, Everett E, Fardo DW, Friend SH, Frohlich H, Gan J, St George-Hyslop P, Ghosh SS, Glaab E, Green RC, Guan Y, Hong MY, Huang C, Hwang J, Ibrahim J, Inglese P, lyappan A, Jiang Q, Katsumata Y, Kauwe JS, Klein A, Kong D, Krause R, Lalonde E, Lauria M, Lee E, Lin X, Liu Z, Livingstone J, Logsdon BA, Lovestone S, Ma TW, Malhotra A, Mangravite LM, Maxwell TJ, Merrill E, Nagorski J, Namasivayam A, Narayan M, Naz M, Newhouse SJ, Norman TC, Nurtdinov RN, Oyang YJ, Pawitan $Y$, Peng S, Peters MA, Piccolo SR, Praveen P, Priami C, Sabelnykova VY, Senger $P$, Shen $X$, Simmons A, Sotiras A, Stolovitzky G, Tangaro S, Tateo A, Tung YA, Tustison NJ, Varol E, Vradenburg G, Weiner MW, Xiao G, Xie L, Xie Y, Xu J, Yang H, Zhan X, Zhou Y, Zhu F, Zhu H, Zhu S, and Alzheimer's Disease Neuroimaging I. 2016. Crowdsourced estimation of cognitive decline and resilience in Alzheimer's disease. Alzheimers Dement 12:645-653. 10.1016/j.jalz.2016.02.006

Ardal C, and Rottingen JA. 2012. Open source drug discovery in practice: a case study. PLoS Negl Trop Dis 6:e1827. 10.1371/journal.pntd.0001827 
393

Ardal C, and Rottingen JA. 2015. An open source business model for malaria. PLoS One 10:e0117150. 10.1371/journal.pone.0117150

Arshad Z, Smith J, Roberts M, Lee WH, Davies B, Bure K, Hollander GA, Dopson S, Bountra C, and Brindley D. 2016. Open Access Could Transform Drug Discovery: A Case Study of JQ1. Expert Opin Drug Discov 11:321-332. 10.1517/17460441.2016.1144587

Austen-Smith D, and Banks JS. 1996. Information aggregation, rationality, and the Condorcet Jury Theorem. American Political Science Review 90:34-45.

Bagla P. 2012. Science in India. Crowd-sourcing drug discovery. Science 335:909. 10.1126/science.335.6071.909

Ballell L, Bates RH, Young RJ, Alvarez-Gomez D, Alvarez-Ruiz E, Barroso V, Blanco D, Crespo B, Escribano J, Gonzalez R, Lozano S, Huss S, Santos-Villarejo A, Martin-Plaza JJ, Mendoza A, Rebollo-Lopez MJ, Remuinan-Blanco M, Lavandera JL, Perez-Herran E, Gamo-Benito FJ, Garcia-Bustos JF, Barros D, Castro JP, and Cammack N. 2013. Fueling open-source drug discovery: 177 small-molecule leads against tuberculosis. ChemMedChem 8:313-321. 10.1002/cmdc.201200428

Bhardwaj A, Scaria V, Raghava GP, Lynn AM, Chandra N, Banerjee S, Raghunandanan MV, Pandey V, Taneja B, Yadav J, Dash D, Bhattacharya J, Misra A, Kumar A, Ramachandran S, Thomas Z, Open Source Drug Discovery C, and Brahmachari SK. 2011. Open source drug discovery--a new paradigm of collaborative research in tuberculosis drug development. Tuberculosis (Edinb) 91:479-486. 10.1016/j.tube.2011.06.004

Bombelles T, and Coaker H. 2015. Neglected tropical disease research: rethinking the drug discovery model. Future Med Chem 7:693-700. 10.4155/fmc.15.29

Brabham DC. 2008. Crowdsourcing as a model for problem solving: An introduction and cases. Convergence 14:75-90.

Brabham DC, Ribisl KM, Kirchner TR, and Bernhardt JM. 2014. Crowdsourcing applications for public health. Am J Prev Med 46:179-187. 10.1016/j.amepre.2013.10.016

Bradbury H. 2015. The SAGE handbook of action research / edited by Hilary Bradbury. Los Angeles: SAGE Publications.

Cammarota J, and Fine M. 2008. Revolutionizing education : youth participatory action research in motion. New York, NY: Routledge.

Cammarota J, and Fine M. 2010. Revolutionizing education: Youth participatory action research in motion: Routledge.

Chesbrough HW. 2003. Open innovation : the new imperative for creating and profiting from technology. Boston, Mass.: Harvard Business School Press.

Crequit P, Mansouri G, Benchoufi M, Vivot A, and Ravaud P. 2018. Mapping of Crowdsourcing in Health: Systematic Review. J Med Internet Res 20:e187. 10.2196/jmir.9330

Dai JC, Lendvay TS, and Sorensen MD. 2017. Crowdsourcing in Surgical Skills Acquisition: A Developing Technology in Surgical Education. J Grad Med Educ 9:697-705. 10.4300/JGME-D-17-00322.1

de Condorcet M. 1785. Essai sur l'application de l'analyse à la probabilité des décisions rendues à la pluralité des voix. Available at http://gallica.bnf.fr/ark:/12148/bpt6k417181.

Desselle MR, Neale R, Hansford KA, Zuegg J, Elliott AG, Cooper MA, and Blaskovich MA. 2017. Institutional profile: Community for Open Antimicrobial Drug Discovery - crowdsourcing new antibiotics and antifungals. Future Sci OA 3:FSO171. 10.4155/fsoa-2016-0093

Diamond IR, Grant RC, Feldman BM, Pencharz PB, Ling SC, Moore AM, and Wales PW. 2014. Defining consensus: a systematic review recommends methodologic criteria for reporting of Delphi studies. J Clin Epidemiol 67:401-409. 10.1016/j.jclinepi.2013.12.002

Ellis-Petersen H. 2016. Boaty McBoatface wins poll to name polar research vessel. Guardian. 
439

440

441

442

443

444

445

446

447

448

449

450

451

452

453

454

455

456

457

458

459

460

461

462

463

464

465

466

467

468

469

470

471

472

473

474

475

476

477

478

479

480

481

482

483

484

485

English PB, Richardson MJ, and Garzon-Galvis C. 2018. From Crowdsourcing to Extreme Citizen Science: Participatory Research for Environmental Health. Annu Rev Public Health 39:335-350.

10.1146/annurev-publhealth-040617-013702

Fitzpatrick T, Zhou K, Cheng Y, Chan PL, Cui F, Tang W, Mollan KR, Guo W, and Tucker JD. 2018. A crowdsourced intervention to promote hepatitis $B$ and $C$ testing among men who have sex with men in China: study protocol for a nationwide online randomized controlled trial. BMC Infect Dis 18:489. 10.1186/s12879-018-3403-3

Fu S, de Vreede G-J, Cheng X, Seeber I, Maier R, and Weber B. 2017. Convergence of Crowdsourcing Ideas: A Cognitive Load perspective. ICIS 2017 PROCEEDINGS Association for Information Systems.

Geiger D, Rosemann M, and Fielt E. 2011a. Crowdsourcing Information Systems - A Systems Theory Perspective. 22nd Australasian Conference on Information Systems. Sydney, Australia.

Geiger D, Rosemann M, and Fielt E. 2011b. Crowdsourcing information systems: a systems theory perspective. 22nd Australian Conference on Information Systems. Sydney, Australia.

Gottlieb K, and Hussain F. 2015. Voting for image scoring and assessment (VISA)--theory and application of a $2+1$ reader algorithm to improve accuracy of imaging endpoints in clinical trials. BMC Med Imaging 15:6. 10.1186/s12880-015-0049-0

Grammer AC, Ryals MM, Heuer SE, RobI RD, Madamanchi S, Davis LS, Lauwerys B, Catalina MD, and Lipsky PE. 2016. Drug repositioning in SLE: crowd-sourcing, literature-mining and Big Data analysis. Lupus 25:1150-1170. 10.1177/0961203316657437

Guinney J, Wang T, Laajala TD, Winner KK, Bare JC, Neto EC, Khan SA, Peddinti G, Airola A, Pahikkala T, Mirtti T, Yu T, Bot BM, Shen L, Abdallah K, Norman T, Friend S, Stolovitzky G, Soule H, Sweeney CJ, Ryan CJ, Scher HI, Sartor O, Xie Y, Aittokallio T, Zhou FL, Costello JC, and Prostate Cancer Challenge DC. 2017. Prediction of overall survival for patients with metastatic castrationresistant prostate cancer: development of a prognostic model through a crowdsourced challenge with open clinical trial data. Lancet Oncol 18:132-142. 10.1016/S1470-2045(16)305605

Han L, Chen A, Wei S, Ong JJ, Iwelunmor J, and Tucker JD. 2018. Crowdsourcing Contests in Health and Health Research: A Practical Guide. Geneva: World Health Organization.

Hautz WE, Kammer JE, Schauber SK, Spies CD, and Gaissmaier W. 2015. Diagnostic performance by medical students working individually or in teams. JAMA 313:303-304. 10.1001/jama.2014.15770

Howe J. 2006. The Rise of Crowdsourcing. Wired.

Janis IL. 1972. Victims of groupthink; a psychological study of foreign-policy decisions and fiascoes. Boston,: Houghton.

Jones RB, Goldsmith L, Hewson P, and Williams CJ. 2013. Recruitment to online therapies for depression: pilot cluster randomized controlled trial. J Med Internet Res 15:e45. 10.2196/jmir.2367

Kammer JE, Hautz WE, Herzog SM, Kunina-Habenicht O, and Kurvers R. 2017. The Potential of Collective Intelligence in Emergency Medicine: Pooling Medical Students' Independent Decisions Improves Diagnostic Performance. Med Decis Making 37:715-724. 10.1177/0272989X17696998

Kirshner B. 2010. Productive Tensions in Youth Participatory Action Research. Yearbook of the National Society for the Study of Education 109:238-251.

Koch T, and Ridgley M. 2000. The Condorcet's Jury Theorem in a Bioethical Context: The Dynamics of Group Decision Making. Group Decision and Negotiation 9:379-392.

Kurvers RH, Herzog SM, Hertwig R, Krause J, Carney PA, Bogart A, Argenziano G, Zalaudek I, and Wolf M. 2016. Boosting medical diagnostics by pooling independent judgments. Proc Natl Acad Sci U S A 113:8777-8782. 10.1073/pnas.1601827113

Peer] reviewing PDF | (2018:10:32351:2:1:NEW 5 Mar 2019) 
486

487

488

489

490

491

492

493

494

495

496

497

498

499

500

501

502

503

504

505

506

507

508

509

510

511

512

513

514

515

516

517

518

519

520

521

522

523

524

525

526

527

528

529

530

531

532

Ladha KK. 1992. The Condorcet Jury Theorem, Free Speech, and Correlated Votes. American Journal of Political Science 36:617-634.

Larson HJ, Smith DM, Paterson P, Cumming M, Eckersberger E, Freifeld CC, Ghinai I, Jarrett C, Paushter L, Brownstein JS, and Madoff LC. 2013. Measuring vaccine confidence: analysis of data obtained by a media surveillance system used to analyse public concerns about vaccines. Lancet Infect Dis 13:606-613. 10.1016/S1473-3099(13)70108-7

Lavorgna L, Lanzillo R, Brescia Morra V, Abbadessa G, Tedeschi G, and Bonavita S. 2017. Social Media and Multiple Sclerosis in the Posttruth Age. Interact J Med Res 6:e18. 10.2196/ijmr.7879

Leiter A, Sablinski T, Diefenbach M, Foster M, Greenberg A, Holland J, Oh WK, and Galsky MD. 2014. Use of crowdsourcing for cancer clinical trial development. J Natl Cancer Inst 106. $10.1093 /$ jnci/dju258

Lévy P. 1997. Collective intelligence : mankind's emerging world in cyberspace. New York: Plenum Trade.

Lim W, Melse Y, Konings M, Phat Duong H, Eadie K, Laleu B, Perry B, Todd MH, loset JR, and van de Sande WWJ. 2018. Addressing the most neglected diseases through an open research model: The discovery of fenarimols as novel drug candidates for eumycetoma. PLoS Negl Trop Dis 12:e0006437. 10.1371/journal.pntd.0006437

Losina E, Michl GL, Smith KC, and Katz JN. 2017. Randomized Controlled Trial of an Educational Intervention Using an Online Risk Calculator for Knee Osteoarthritis: Effect on Risk Perception. Arthritis Care Res (Hoboken) 69:1164-1170. 10.1002/acr.23136

Mackay C. 1852. Memoirs of extraordinary popular delusions and the madness of crowds. London: Office of the National Illustrated Library.

Manstead ASR, and Hewstone M. 1995. The Blackwell encyclopedia of social psychology. Oxford, UK ; Cambridge, Mass., USA: Blackwell.

Mathews A, Farley S, Blumberg M, Knight K, Hightow-Weidman L, Muessig K, Rennie S, and Tucker J. 2017. HIV cure research community engagement in North Carolina: a mixed-methods evaluation of a crowdsourcing contest. J Virus Erad 3:223-228.

Mathews A, Farley S, Hightow-Weidman L, Muessig K, Rennie S, and Tucker JD. 2018. Crowdsourcing and community engagement: a qualitative analysis of the 2BeatHIV contest. $J$ Virus Erad 4:3036.

McElfish PA, Kohler P, Smith C, Warmack S, Buron B, Hudson J, Bridges M, Purvis R, and Rubon-Chutaro J. 2015. Community-Driven Research Agenda to Reduce Health Disparities. Clin Trans/ Sci 8:690695. 10.1111/cts.12350

McPhail C. 1991. The Myth of the Madding Crowd. Social Forces.

Minkler M, and Wallerstein N. 2003. Community based participatory research for health. San Francisco, CA: Jossey-Bass.

Mortensen ML, Adam GP, Trikalinos TA, Kraska T, and Wallace BC. 2017. An exploration of crowdsourcing citation screening for systematic reviews. Res Synth Methods 8:366-386. 10.1002/jrsm.1252

Mudie LI, Wang X, Friedman DS, and Brady CJ. 2017. Crowdsourcing and Automated Retinal Image Analysis for Diabetic Retinopathy. Curr Diab Rep 17:106. 10.1007/s11892-017-0940-x

Munos B. 2006. Can open-source R\&D reinvigorate drug research? Nat Rev Drug Discov 5:723-729. $10.1038 / \mathrm{nrd} 2131$

Munos B. 2010. Can open-source drug R\&D repower pharmaceutical innovation? Clin Pharmacol Ther 87:534-536. 10.1038/clpt.2010.26

Noren DP, Long BL, Norel R, Rrhissorrakrai K, Hess K, Hu CW, Bisberg AJ, Schultz A, Engquist E, Liu L, Lin $X$, Chen GM, Xie H, Hunter GA, Boutros PC, Stepanov O, Consortium DA-O, Norman T, Friend SH, Stolovitzky G, Kornblau S, and Qutub AA. 2016. A Crowdsourcing Approach to Developing and

Peer) reviewing PDF | (2018:10:32351:2:1:NEW 5 Mar 2019) 
Assessing Prediction Algorithms for AML Prognosis. PLoS Comput Biol 12:e1004890. 10.1371/journal.pcbi.1004890

Orionzi DE, Mink PJ, Azzahir A, Yusuf AA, Jernigan MJ, Dahlem JL, Anderson MJ, Trahan L, and Rosenberg-Carlson E. 2016. Implementing a Community-Driven Research Partnership: The Backyard Initiative Community Health Survey Methods and Approach. Prog Community Health Partnersh 10:493-503. 10.1353/cpr.2016.0057

Ozer EJ. 2016. Chapter Seven-Youth-Led Participatory Action Research: Developmental and Equity Perspectives. Advances in child development and behavior 50:189-207.

Ozer EJ, Piatt AA, Holsen I, Larsen T, Lester J, and Ozer EM. 2016. INNOVATIVE APPROACHES TO PROMOTING POSITIVE YOUTH DEVELOPMENT IN DIVERSE CONTEXTS. Positive Youth Development in Global Contexts of Social and Economic Change:12.

Pan SW, Stein G, Bayus B, Mathews A, Wang C, Wei C, and Tucker JD. 2017. Systematic review of design contests for health: Spurring innovation and mass engagement. BMJ Innovations 3:227-237.

Powell GA, Zinszer K, Verma A, Bahk C, Madoff L, Brownstein J, and Buckeridge D. 2016. Media content about vaccines in the United States and Canada, 2012-2014: An analysis using data from the Vaccine Sentimeter. Vaccine 34:6229-6235. 10.1016/j.vaccine.2016.10.067

Ranard BL, Ha YP, Meisel ZF, Asch DA, Hill SS, Becker LB, Seymour AK, and Merchant RM. 2014. Crowdsourcing--harnessing the masses to advance health and medicine, a systematic review. J Gen Intern Med 29:187-203. 10.1007/s11606-013-2536-8

Rice S, Robinson J, Bendall S, Hetrick S, Cox G, Bailey E, Gleeson J, and Alvarez-Jimenez M. 2016. Online and Social Media Suicide Prevention Interventions for Young People: A Focus on Implementation and Moderation. J Can Acad Child Adolesc Psychiatry 25:80-86.

Ringh $M$, Rosenqvist $M$, Hollenberg J, Jonsson $M$, Fredman D, Nordberg $P$, Jarnbert-Pettersson $H$, Hasselqvist-Ax I, Riva G, and Svensson L. 2015. Mobile-phone dispatch of laypersons for CPR in out-of-hospital cardiac arrest. N Engl J Med 372:2316-2325. 10.1056/NEJMoa1406038

Rohde H, Qin J, Cui Y, Li D, Loman NJ, Hentschke M, Chen W, Pu F, Peng Y, Li J, Xi F, Li S, Li Y, Zhang Z, Yang X, Zhao M, Wang P, Guan Y, Cen Z, Zhao X, Christner M, Kobbe R, Loos S, Oh J, Yang L, Danchin A, Gao GF, Song Y, Li Y, Yang H, Wang J, Xu J, Pallen MJ, Wang J, Aepfelbacher M, Yang $\mathrm{R}$, and Consortium EcOHGAC-S. 2011. Open-source genomic analysis of Shiga-toxin-producing $\mathrm{E}$. coli 0104:H4. N Engl J Med 365:718-724. 10.1056/NEJMoa1107643

Saez-Rodriguez J, Costello JC, Friend SH, Kellen MR, Mangravite L, Meyer P, Norman T, and Stolovitzky G. 2016. Crowdsourcing biomedical research: leveraging communities as innovation engines. Nat Rev Genet 17:470-486. 10.1038/nrg.2016.69

Scott AR. 2016. Chemical probes: A shared toolbox. Nature 533:S60-61. 10.1038/533S60a

Shaw DL. 2017. Is Open Science the Future of Drug Development? Yale J Biol Med 90:147-151.

Siefert AL, Cartiera MS, Khalid AN, Nantel MC, Loose CR, Schulam PG, Saltzman WM, and Dempsey MK. 2018. The Yale Center for Biomedical Innovation and Technology (CBIT): One Model to Accelerate Impact From Academic Health Care Innovation. Acad Med. 10.1097/ACM.0000000000002542

So AD, Gupta N, Brahmachari SK, Chopra I, Munos B, Nathan C, Outterson K, Paccaud JP, Payne DJ, Peeling RW, Spigelman M, and Weigelt J. 2011. Towards new business models for R\&D for novel antibiotics. Drug Resist Updat 14:88-94. 10.1016/j.drup.2011.01.006

Spangenberg T, Burrows JN, Kowalczyk P, McDonald S, Wells TN, and Willis P. 2013. The open access malaria box: a drug discovery catalyst for neglected diseases. PLoS One 8:e62906. 10.1371/journal.pone.0062906

Surowiecki J. 2004. The wisdom of crowds : why the many are smarter than the few and how collective wisdom shapes business, economies, societies, and nations. New York: Doubleday :. 
580

581

582

583

584

585

586

587

588

589

590

591

592

593

594

595

596

597

598

599

600

601

602

603

604

605

606

607

608

609

610

611

612

613

614

615

616

617

618

619

620

621

622

623

624

625
Tang W, Han L, Best J, Zhang Y, K. M, Kim J, Liu F, Hudgens M, Bayus B, Terris-Prestholt F, Galler S, Yang L, Peeling R, Volberding P, Ma B, Xu H, Yang B, Huang S, Fenton K, Wei C, and Tucker JD. 2016a. Crowdsourcing HIV Testing: A Pragmatic, Non-Inferiority Randomized Controlled Trial in China. Clinical Infectious Diseases 62:1436-1442.

Tang W, Mao J, Liu C, Mollan K, Li H, Wong T, Zhang Y, Tang S, Hudgens M, Qin Y, Ma B, Liao M, Yang B, Ma W, Kang D, Wei C, and Tucker JD. 2016b. Crowdsourcing health communication about condom use in men who have sex with men in China: a randomised controlled trial. Lancet 388 (Suppl 1):S73.

Tang W, Mao J, Liu C, Mollan K, Li H, Wong T, Zhang Y, and Tucker JD. 2016c. Reimagining Health Communication: A Non-Inferiority Randomized Controlled Trial of Crowdsourcing in China. Sex Trans Dis.

Tang W, Wei C, Cao B, Wu D, Li KT, Lu H, Ma W, Kang D, Li H, Liao M, Mollan KR, Hudgens MG, Liu C, Huang W, Liu A, Zhang Y, Smith MK, Mitchell KM, Ong JJ, Fu H, Vickerman P, Yang L, Wang C, Zheng $\mathrm{H}$, Yang B, and Tucker JD. 2018. Crowdsourcing to expand HIV testing among men who have sex with men in China: A closed cohort stepped wedge cluster randomized controlled trial. PLoS Med 15:e1002645. 10.1371/journal.pmed.1002645

Tucker JD, Pan SW, Mathews A, Stein G, Bayus B, and Rennie S. 2018. Crowdsourcing Contests: A Scoping Review on Ethical Concerns And Risk Mitigation Strategies. Journal of Medical Internet Research.

Tuffery P. 2015. Accessing external innovation in drug discovery and development. Expert Opin Drug Discov 10:579-589. 10.1517/17460441.2015.1040759

van Ess H. 2010. Crowdsourcing: How to find a crowd. Available at https://www.slideshare.net/searchbistro/harvesting-knowledge-how-to-crowdsource-in-2010. von Hippel E, and von Krogh G. 2003. Open Source Software and the "Private-Collective" Innovation Model: Issues for Organization Science. Organization Science 14:209-223.

Wang C, Han L, Stein G, Day S, Bien-Gund C, Mathews A, Ong JJ, Zhao P, Wei S, Walker J, Chou R, Lee A, Chen A, Bayus B, and Tucker JD. 2018. Crowdsourcing in Health and Medical Research: A Systematic Review. LSHTM Evaluation Series. London, UK.

Wang C, Mollan KR, Hudgens MG, Tucker JD, Zheng H, Tang W, and Ling L. 2017. Generalisability of an online randomised controlled trial: an empirical analysis. J Epidemiol Community Health. 10.1136/jech-2017-209976

Wazny K. 2017. "Crowdsourcing" ten years in: A review. J Glob Health 7:020602. 10.7189/jogh.07.020602

Wells HG. 1938. World brain. Garden City, N.Y.,: Doubleday, Doran \& Co., Inc.

Wilhelm M. 2017. Big Pharma Buys Into Crowdsourcing for Drug Discovery. Wired.

Wolf M, Krause J, Carney PA, Bogart A, and Kurvers RH. 2015. Collective Intelligence Meets Medical Decision-Making: The Collective Outperforms the Best Radiologist. PLoS One 10:e0134269. 10.1371/journal.pone.0134269

Woolley AW, Chabris CF, Pentland A, Hashmi N, and Malone TW. 2010. Evidence for a Collective Intelligence Factor in the Performance of Human Groups. Science 330:686-688.

Wu D, Best LL, Stein G, Tang W, Tucker JD, and Healthy Cities Contest T. 2018. Community participation in a Lancet Healthy Cities in China Commission. Lancet Planet Health 2:e241-e242. 10.1016/S2542-5196(18)30083-4

Zhang A, Pan X, Wu F, Zhao Y, Hu F, Li L, Cai W, and Tucker JD. 2017a. What Would an HIV Cure Mean to You: Qualitative Analysis from a Crowdsourcing Contest in Guangzhou, China. AIDS Res Hum Retroviruses. 10.1089/AID.2017.0188

Peer] reviewing PDF | (2018:10:32351:2:1:NEW 5 Mar 2019) 
626 Zhang W, Schaffer D, Tso LS, Tang S, Tang W, Huang S, Yang B, and Tucker JD. 2017b. Innovation

627

628

629

630

631

632 contests to promote sexual health in China: a qualitative evaluation. BMC Public Health 17:78. 10.1186/s12889-016-4006-9

Zhang Y, Kim J, Liu F, Tso L, Tang W, Wei C, Bayus B, and Tucker JD. 2015. Creative contributory contests (CCC) to spur innovation in sexual health: Two cases and a guide for implementation. Sex Transm Dis 42:625-628. 


\section{Table 1 (on next page)}

Crowdsourcing activities used to improve medical research: structure and function.

Crowdsourcing activities in medical research include innovation challenges, hackathons, and online collaboration systems. 
Table 1. Crowdsourcing activities used to improve medical research: structure and function

\begin{tabular}{|l|l|l|}
\hline $\begin{array}{l}\text { Crowdsourcing } \\
\text { activity }\end{array}$ & Structure & Function \\
\hline $\begin{array}{l}\text { Innovation } \\
\text { challenges }\end{array}$ & $\begin{array}{l}\text { Open solicitation and } \\
\text { promotion to the public for } \\
\text { challenge submissions; } \\
\text { evaluation, celebration, and } \\
\text { sharing of challenge } \\
\text { submissions }\end{array}$ & $\begin{array}{l}\text { Generate innovative ideas, logos, images, } \\
\text { or videos (e.g., images to increase HIV } \\
\text { testing, strategies to promote hepatitis } \\
\text { testing); accelerate pharmaceutical drug } \\
\text { development }\end{array}$ \\
\hline Hackathons & $\begin{array}{l}\text { Short (often 3 days) event } \\
\text { that brings together } \\
\text { individuals around a } \\
\text { common cause }\end{array}$ & $\begin{array}{l}\text { Design a clinical algorithm, prevention } \\
\text { service (e.g., design an HIV testing } \\
\text { service), or new technology }\end{array}$ \\
\hline $\begin{array}{l}\text { Online } \\
\text { collaboration } \\
\text { systems }\end{array}$ & $\begin{array}{l}\text { Websites or portals that } \\
\text { allow individuals to solve a } \\
\text { problem }\end{array}$ & $\begin{array}{l}\text { Solve micro-tasks for a small amount of } \\
\text { money (e.g., evaluation of surgical skills) }\end{array}$ \\
\hline
\end{tabular}




\section{Table 2 (on next page)}

Comparison of conventional medical research and crowdsourced approaches.

Most medical research uses a framework of closed innovation (middle column).

Crowdsourcing proposes an open innovation approach (right column). 
1

2 Table 2. Comparison of conventional medical research and crowdsourced approaches.

\begin{tabular}{|l|l|l|}
\hline & $\begin{array}{l}\text { Conventional medical research } \\
\text { (closed innovation) }\end{array}$ & $\begin{array}{l}\text { Crowdsourced approach (open } \\
\text { innovation) }\end{array}$ \\
\hline $\begin{array}{l}\text { Medical research } \\
\text { questions }\end{array}$ & $\begin{array}{l}\text { Those with medical research } \\
\text { skills know best how to frame } \\
\text { questions. }\end{array}$ & $\begin{array}{l}\text { A diverse group of individuals } \\
\text { together know best how to frame } \\
\text { questions. }\end{array}$ \\
\hline $\begin{array}{l}\text { Methods for } \\
\text { innovation }\end{array}$ & $\begin{array}{l}\text { Internal teams led by experts, } \\
\text { with little input from outside }\end{array}$ & $\begin{array}{l}\text { Collaborative co-creation with non- } \\
\text { experts and the public engaged }\end{array}$ \\
\hline $\begin{array}{l}\text { Intellectual } \\
\text { property }\end{array}$ & $\begin{array}{l}\text { Focus on controlling IP so that } \\
\text { competitors will not benefit }\end{array}$ & $\begin{array}{l}\text { Use others' IP when it advances the } \\
\text { research }\end{array}$ \\
\hline
\end{tabular}

3

4 


\section{Table 3(on next page)}

Crowdsourcing applications in medical research.

Crowdsourcing can be used to inform formative work, pre-clinical research, and clinical research. 
Table 3. Crowdsourcing applications in medical research.

\begin{tabular}{|l|l|l|}
\hline $\begin{array}{l}\text { Crowdsourcing } \\
\text { Application }\end{array}$ & $\begin{array}{l}\text { Purpose of } \\
\text { Crowdsourcing }\end{array}$ & Examples \\
\hline $\begin{array}{l}\text { Informing medical } \\
\text { research (formative) }\end{array}$ & Optimize search processes & Assist with systematic reviews \\
\hline Pre-clinical research & $\begin{array}{l}\text { Share key elements } \\
\text { necessary for drug } \\
\text { development }\end{array}$ & $\begin{array}{l}\text { Curate data on drugs; Accelerate } \\
\text { genomic analysis }\end{array}$ \\
\hline $\begin{array}{l}\text { Clinical and } \\
\text { translational research }\end{array}$ & $\begin{array}{l}\text { Recruiting study } \\
\text { participants; community } \\
\text { engagement }\end{array}$ & $\begin{array}{l}\text { Solicit community feedback; enhance } \\
\text { drug development }\end{array}$ \\
\hline
\end{tabular}

1 